\title{
The road to hell is paved with good intentionality
}

\author{
Carin-Isabel Knoop
}

Executive Director at Harvard Business School

Harvard University, Massachusetts, USA

\section{Abstract}

The dislocation of the Pandemic caused social convulsions around the world. The middle and ruling classes seem to have rediscovered humans - essential workers, employees, members of underrepresented minorities, and children.

In our rush to atone our sins and redress imbalances, we are not stopping to define words nor, as the pragmatists would want us to, think through what our moral precepts mean in practice. Nor do we have the tools in accounting, the "language of business," to capture our efforts.

However, teams that do not take the time to establish ground rules and standard definitions often get a faster start but don't always do the best work nor have the most impact. Let's give ourselves better changes.

Keywords: diversity; equity; language; pragmatism.

"A wise man apportions his beliefs to the evidence."

- David Hume

In France, 1968 was a year of both social dislocation and possibility. The young protested for more justice, questioned the status quo, blamed their elders and capitalism for the world's ills; workers pushed for better conditions and more rights; politicians responded with deep reforms.

In the United States, 1968 brought the opposite of possibility-the assassinations of Martin Luther King Jr and Robert Kennedy, new escalation in the Vietnam War, and student protests crushed by police at the Democratic National Convention.

We are in a similar place today, caught between both experiences. The Covid crisis has pushed people around the world to demonstrate heroic strength while revealing profound weaknesses in our society. Widening gaps in income, wealth, and opportunity in the years before the virus hit left everyone more vulnerable to the disease and the attendant chaos.

The crucible of this crisis provides the unique opportunity to begin to put things right, to ensure that societies emerge more equitable, sustainable, and resilient. We seem to have rediscovered humans - essential workers, employees, children, and 
adolescents. Companies are making grand promises about being instruments for good and becoming more "human" and create a more equitable world.

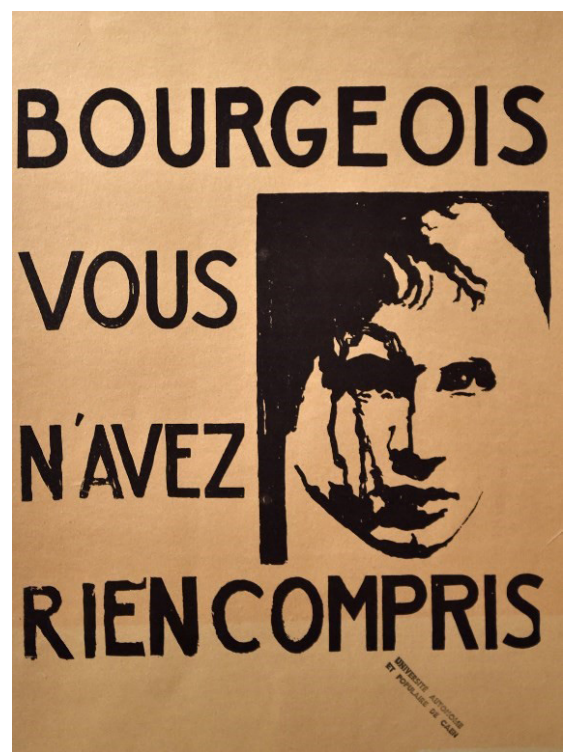

Figure 1. Photo by AFP: "Bourgeois, you did not understand anything" / May 1968 French protest poster

To ensure that we emerge from the Pandemic better able to understand and improve ourselves, each other, and society, we need to define more and assume less. To guide and adjust actions, we need data and the willingness to talk about language. Corporate and public initiatives should be clear about the problems, potential solutions, and risks they entail. They should address causes, not just consequences. However, most responses have been reactive, emotional, and predictable. And very few have included specific definitions of what these concepts, which have been around for decades, mean today.

Unfortunately, it can feel costly to ask for definitions in business and educational environments. Do we all have a common understanding of what anti-racism, equity, and inclusion mean? More importantly, how do we derive a common understanding of what they mean in practice? The poster from the May 1968 revolt claimed that the bourgeois class had not understood anything, that it was clueless. Given another chance, will today's "well"-"meaning" middle class try to understand what social phenomena really imply and mean, and not just parrot what they believe is expected at the moment? Put another way, can we be pragmatic on these central issues of our time to drive moral and social goals without being dismissed as heretical? 


\section{What do we mean by "over"?}

In the word "communication" appears "commun," meaning "in common" in French. Language enables society and human interaction by making possible cooperation and the exchange of information.

Although we create words to describe our reality, billions have subsequently received them from parents, schools, literature, social media, and friends. Sometimes the terms are defined; sometimes they are not. Rarely are we explicit about the meaning we give them. We accept that we perceive colors differently, but assume that we hear words similarly.

We are rarely explicit about the meanings we assign to them. Two individuals can describe themselves as sad, but neither will ever know how sadness feels to the other. Rather, they ascribe meaning to the indications of sadness that they can observe-a look, a gait, an affect. If you tell colleagues "I am stressed today," some may interpret this as a plea to be left alone or treated gingerly when it could in fact be a call for help, support, or connection. Rarely do we ask what the person means or needs - we take our cues from the interpretations of others.

Consider the apparently simple word "over." It is a preposition, a noun, and an adverb. Often these days we hear: "the pandemic is over." Or in the American colloquialism: "I am so over it." What do we mean here by "over"? For my father, a Nazi teenage youth leader, WWII is not over - and never will be.

\section{Whose equity?}

We deal with much more complexwords than "other" in social and political conversation (in person and online). But here, too, we assume that we have the same definition of key concepts or words. We take the path of least resistance and greatest emotional payoff. For loaded words such as "racism," "equity," and "gender," we maintain our individual sense of what concepts such as these mean to us. When we are asked to explain what we mean by them, we often realize that we don't really know what we mean. The same holds true of those who profess to be in the know. Many D\&l experts don't have ready definitions.

Equity has become the word of the moment (from the word aequitas), or fairness. But also in the sense of shareholder equity or equity markets. As market equity grew, economic equity fell.

Romans used accounting to assess "the moral position of a citizen in relation to the others in the same community." In accounting, we refer to shareholder equity, which makes the balance sheet a "store of fairness." In Summa de arithmetica, geometria, proportioni et proportionalita, Luca Pacioli saw promise and wisdom in double-entry 
bookkeeping as a tool to make sure that its users made balanced decisions. Wisdom, he and other religious accounting writers noted, lies not at the extremes but in the middle: in medio stat virtus. We have come a long way-in the wrong direction.

Another word of the moment is "intentional," as in, "let us be intentional about diversity and inclusion" - as in "let us intend to improve D\&I outcomes by focusing energy and effort on bringing about positive change." The term "intentionality" was popularized by German philosopher Franz Brentano in the late 19th century, and lies at the confluence of the philosophy of language and the philosophy of mind. But it is tricky when we use the term to describe social phenomena because, in doing so, we follow a personal mental models. The next step has to define the act of doinghow do we make D\&I outcomes better-and not just the act of conceptualizing--what improved D\&l outcomes might look like?

Companies and societies preach empowerment, innovation, and risk-taking - they want their employees to behave like owners and to commit to business outcomes. But in the area of $D \& 1$, many of us don't feel empowered to push back or suggest alternative approaches. Instead of being intentional, we should be explicit about our motivations, goals, methods, actions, and metrics. Anything else will lead to disappointment.

\section{Back to first principles}

We also need to create a new language of business to ensure that public and private organizations are rewarded for investments in humanity. In the current accounting treatment, investments made into programs to support employees and work to promote equity are a cost on the Income Statement. At the same time liabilities that may result from lacking those attributes (which include lost productivity, legal claims, costs of support programs) will not be recognized on the balance sheet and considered remote.

Social and mental health risks must be considered as a potential liability during and after the Pandemic. If the liability is probable, then it should be recognized. Investing into programs to reduce that risk and support employees both reduce the liability and create investment into an organization's reputation with each employee through the license to operate.

Doing so would be going back to Pacioli's intent and reconciling economic equity with shareholder equity-in its purest and oldest sense of the word. 


\section{Bibliography}

1. Hume, David. An enquiry concerning human understanding. Routledge, 2016.

2. McAlister, Linda L. "The philosophy of Brentano." (1976).

3. Pacioli, Luca. Summa de Arithmetica geometria proportioni: et proportionalita... Paganino de paganini, 1994.

4. Photo by AFP: "Bourgeois, you did not understand anything" / May 1968 French protest poster 